\title{
Correction to: 4-Phenylbutyric acid protects against vasculitic peripheral neuropathy induced by ischaemia-reperfusion through attenuating endoplasmic reticulum stress
}

\author{
Cay-Huyen Chen ${ }^{1,2} \cdot$ Ping-Chen Shih ${ }^{1,2} \cdot$ Han-Yu Lin ${ }^{1,2} \cdot$ Po-Kai Wang ${ }^{2} \cdot$ Po-Ting Pan ${ }^{1,2} \cdot$ Ching-Wei Chuang $^{1,2}$. \\ Ming-Chang Kao ${ }^{1,2}$ (i)
}

Published online: 29 June 2020

(c) Springer Nature Switzerland AG 2020

Correction to: Inflammopharmacology (2019) 27:713-722

https://doi.org/10.1007/s10787-019-00604-6

Unfortunately, Fig. 5 was incorrectly published in the original publication. The complete corrected Fig. 5 is given below.

Publisher's Note Springer Nature remains neutral with regard to jurisdictional claims in published maps and institutional affiliations.

The original article can be found online at https://doi.org/10.1007/ s10787-019-00604-6.

Ming-Chang Kao

dr_mck@yahoo.com.tw

1 Department of Anesthesiology, Taipei Tzu Chi Hospital, Buddhist Tzu Chi Medical Foundation, 289, Jianguo Rd.,

Sindian District, New Taipei City 23142, Taiwan

2 School of Medicine, Tzu Chi University, Hualien, Taiwan 
(a)

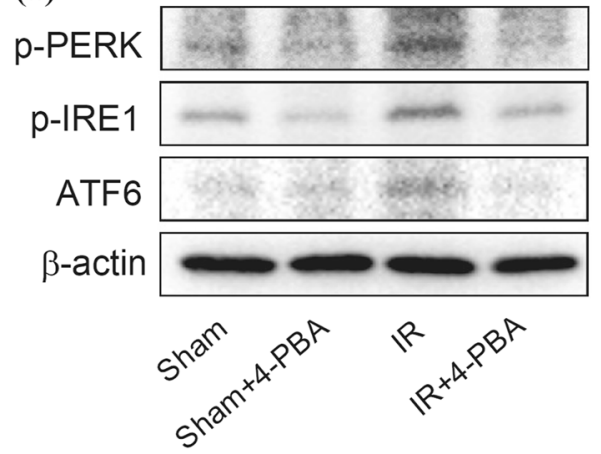

(c)

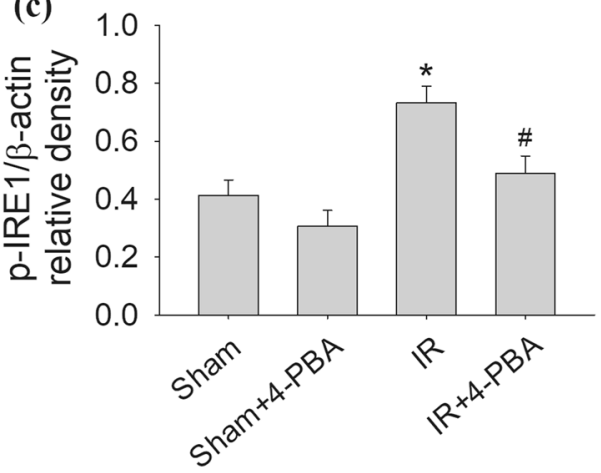

Fig. 5 Effects of 4-phenylbutyric acid (4-PBA) on endoplasmic reticulum stress sensors in the rat sciatic nerves after vasculitic peripheral neuropathy induced by ischaemia-reperfusion (IR) in the femoral artery ( $n=6$ per group). a Representative gel photography of Western blots of phosphorylated protein kinase RNA-like endoplasmic reticulum kinase (p-PERK), phosphorylated inositol-requiring enzyme 1 (p-IRE1) and activating transcription factor 6 (ATF6), b densito- (b)
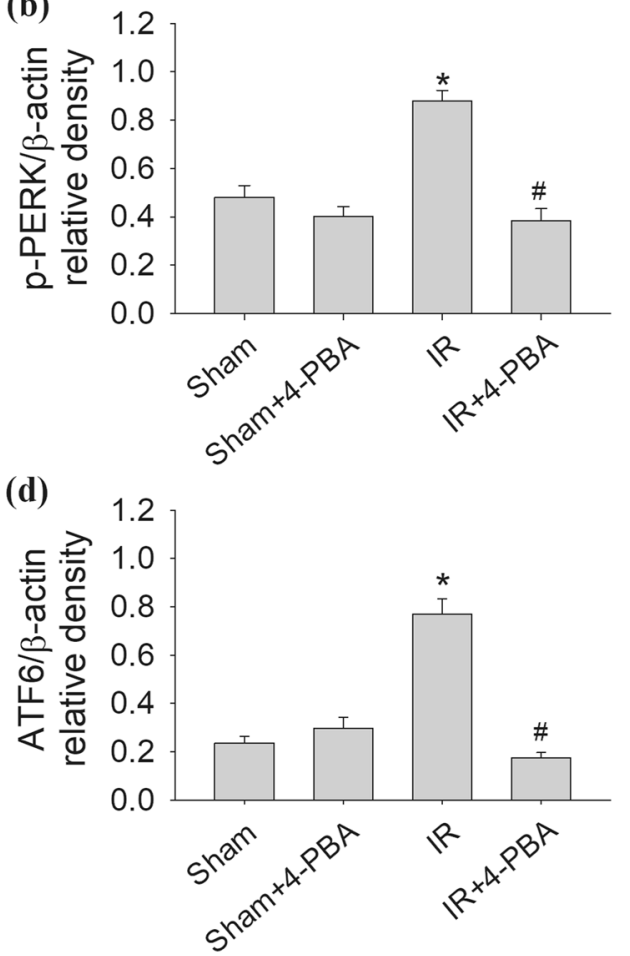

metric analysis of p-PERK expression levels, $\mathbf{c}$ densitometric analysis of p-IRE1 expression levels, $\mathbf{d}$ densitometric analysis of ATF6 expression levels. Sham: the Sham group. Sham +4-PBA: the Sham plus 4-PBA group. IR: the IR group. IR + 4-PBA: the IR plus 4-PBA group. Data were expressed as the mean \pm standard error of means. ${ }^{*} P<0.05$ versus the Sham group. ${ }^{\#} P<0.05$ the IR +4 -PBA group versus the IR group 